\title{
Using satellite radar amplitude imaging for monitoring syn-eruptive changes in surface morphology at an ice-capped stratovolcano
}

Article

Accepted Version

Creative Commons: Attribution-Noncommercial-No Derivative Works 4.0

Arnold, D. W. D., Biggs, J., Wadge, G. and Mothes, P. (2018) Using satellite radar amplitude imaging for monitoring syneruptive changes in surface morphology at an ice-capped stratovolcano. Remote Sensing of the Environment, 209. pp. 480-488. ISSN 0034-4257 doi:

https://doi.org/10.1016/j.rse.2018.02.040 Available at https://centaur.reading.ac.uk/75660/

It is advisable to refer to the publisher's version if you intend to cite from the work. See Guidance on citing.

To link to this article DOI: http://dx.doi.org/10.1016/j.rse.2018.02.040

Publisher: Elsevier

All outputs in CentAUR are protected by Intellectual Property Rights law, including copyright law. Copyright and IPR is retained by the creators or other copyright holders. Terms and conditions for use of this material are defined in the End User Agreement. 


\section{www.reading.ac.uk/centaur}

\section{CentAUR}

Central Archive at the University of Reading

Reading's research outputs online 


\title{
Using satellite radar amplitude imaging for monitoring syn-eruptive changes in surface morphology at an ice-capped stratovolcano
}

\author{
D.W.D. Arnold ${ }^{\mathrm{a}, *}$, J. Biggs ${ }^{\mathrm{a}}$, G. Wadge ${ }^{\mathrm{b}}$, P. Mothes ${ }^{\mathrm{c}}$ \\ ${ }^{a}$ COMET, School of Earth Sciences, University of Bristol, Queens Road, Bristol, BS8 1RJ, UK \\ ${ }^{b}$ COMET, Department of Meteorology, University of Reading, Earley Gate, P.O. Box 243, Reading, RG6 \\ $6 B B, U K$ \\ ${ }^{c}$ Instituto Geofísico, Escuela Politécnica Nacional, Quito, Ecuador
}

\section{Abstract}

Satellite-based measurements of synthetic aperture radar amplitude provide a method for monitoring volcanoes during unrest and eruptions even when visual observations are not possible, for example due to poor weather or at night, and when radar phase measurements are noisy or decorrelated. Here, we use high resolution radar amplitude images from the TerraSAR-X and COSMO SkyMed satellites to investigate surface changes associated with explosive eruptions of Cotopaxi volcano, Ecuador in August 2015. We generate change difference and amplitude ratio maps spanning the start of explosive activity at Cotopaxi, which show complex spatial variations in radar amplitude both on and around the summit ice-cap that we attribute to a number of processes related to the eruption. Observed amplitude decreases are caused by crater deepening, ashfall onto ice and surface smoothing by ashfall onto slopes facing away from the satellite, while amplitude increases are due to deposition of coarse lapilli and wet tephra, increased soil saturation due to geothermally driven glacier melting, and smoothing of slopes facing towards the satellite. We discuss the potential applications of radar amplitude images for monitoring and hazard evaluation at active volcanoes.

9 Keywords: Explosive Volcanism, Radar amplitude, SAR

\footnotetext{
*Corresponding author

Email address: david.arnold@bristol.ac.uk (D.W.D. Arnold)
} 


\section{Introduction}

During periods of volcanic unrest and eruption, frequent observations of the volcano are required to monitor the development of activity, in order to update hazard assessments and protect local populations (e.g. Tilling, 1989; Scarpa and Tilling, 1996; Tilling, 2008). For instance, a volcano with a large, unstable, lava dome growing at the summit will be more prone to a gravitational collapse that could generate large, hazardous, pyroclastic density currents than a volcano without an active dome (e.g. Watts et al., 2002; Sparks, 2003), and changes in the ice-cap at a glaciated volcano could indicate melting that may lead to lahars (e.g. Pierson et al., 1990; Mothes and Vallance, 2015). Up-to-date observations of the morphology and surface state of an erupting volcano are therefore crucial for evaluating the current hazard level.

Observations of volcanoes can be made using a variety of techniques and sensors, but all methods have limitations on either the temporal and/or spatial resolution of information they can provide (e.g. Sparks et al., 2012; Pyle et al., 2013; Biggs and Pritchard, 2017; National Academies of Sciences Engineering and Medicine, 2017). Visual observations are not possible in poor weather conditions such as low lying cloud, which is especially a problem at volcanoes with high relief and/or in tropical regions (e.g. Wadge et al., 2005, 2011). Visual observations are also often not possible at night, and even passive sensors such as thermal IR cameras that can make observations in low light still require clear weather conditions. Ground-based geophysical sensors, such as seismometers and GPS, can make continuous observations regardless of weather conditions, however the information they provide is limited to single locations, and instruments are generally located distally from active vents, due to the difficulty and hazard of deploying, maintaining and preserving proximal instruments, (e.g. Voight et al., 1998; LaHusen et al., 2008; Werner-Allen et al., 2006).

Active radar sensors provide their own illumination, so can make observations at day and night, and operate at wavelengths that are not strongly absorbed or scattered by water droplets or aerosols, so can see through clouds. Synthetic Aperture Radar (SAR) observations can therefore provide additional observations that can complement other monitoring 
techniques. Satellite-based SAR platforms are able to image areas tens to hundreds of kilometres wide with repeat times of days to weeks, and are therefore ideally suited to observations of volcanic systems, especially volcanoes that are difficult to monitor with ground-based techniques due to practical or financial considerations. The frequency of SAR observations can be increased by using images acquired by multiple satellite missions and from different viewing geometries (Elliott et al., 2016).

SAR amplitude observations can provide important observations, even at volcanoes with an established ground-based monitoring network. For instance, amplitude observations showed that the lava dome at Soufrière Hills Volcano, Montserrat had not been destabilised by a large Vulcanian explosion in 2008, thus allowing civil authorities to revoke a precautionary evacuation ten days before visual confirmation was possible (Wadge et al. 2011). Conversely, SAR images provided information about the rate of lava dome growth during the 2010 eruption of Merapi, Indonesia and helped to inform a broader evacuation that potentially saved thousands of lives (e.g. Pallister et al., 2013). SAR amplitude observations have also provided insights into lava flow distribution and morphology at poorly monitored volcanoes (e.g. Wadge et al., 2012; Goitom et al., 2015; Wang et al., 2015), and rockfall response to a tectonic earthquake (Ebmeier et al., 2014).

In this work, we use the August 2015 eruption of Cotopaxi, Ecuador to show the utility of SAR amplitude images for monitoring changes to an ice-capped volcano during explosive eruptions. Cotopaxi is a $5897 \mathrm{~m}$ high stratovolcano located approximately $50 \mathrm{~km}$ south of Quito in the Interandean Valley (Fig. 1). Cotopaxi is one of the most active volcanoes in Ecuador, with nine periods of major historically-observed eruption and at least eight more minor eruptions (Pistolesi et al., 2011). Prior to 2015, the previous eruption of Cotopaxi was a minor explosive episode in 1942 that was confined to the crater (Pistolesi et al., 2011). In April 2015, Instituto Geofisico, Escuela Politecnica Nacional, Ecuador (IG-EPN) reported an increase in seismicity beneath Cotopaxi and $\mathrm{SO}_{2}$ emissions began to increase in May 2015, accompanied by up to $3 \mathrm{~cm}$ of surface uplift (Morales Rivera et al., 2017). Released seismic energy remained above background levels until August 2015, when there was a rapid increase in seismic activity on 13 August 2015 that culminated in four phreatic explosions 

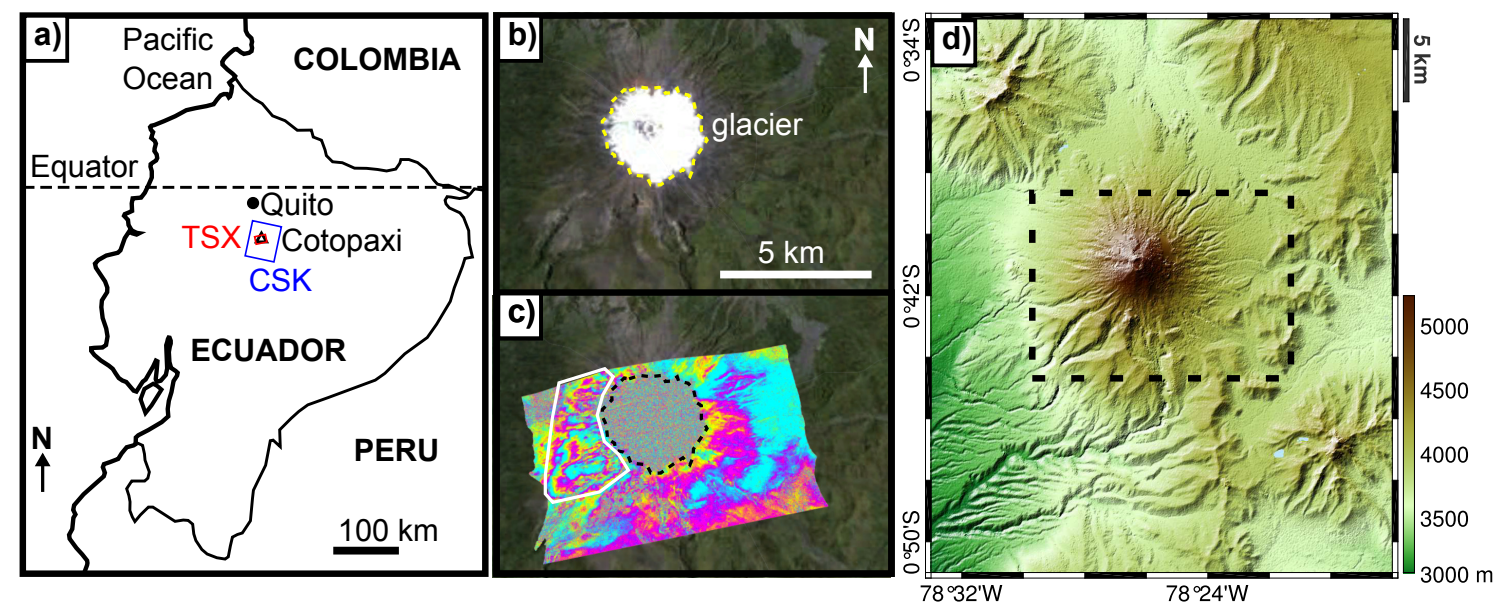

Figure 1: a) Map of Ecuador showing the location of Cotopaxi volcano (black triangle). The red rectangle shows the footprint of the TerraSAR-X (TSX) spotlight image and the blue rectangle shows the area covered by the COSMO-SkyMed (CSK) stripmap acquisitions. b) Google Earth image of Cotopaxi, with the yellow dashed line outlining the snow and ice covered summit. c) Interferogram formed from TSX acquistions on 9 and 20 August 2015. No useful information can be retrieved over the ice-cap (black dashed line) due to phase incoherence. The white polygon west of the glacier shows phase changes due to atmospheric water vapour changes associated with orographic forcing of prevailing westerly winds. Similar phase anomalies are observed in Envisat and Radarsat-2 interferograms spanning 2002-2013, when there was no surface activity at Cotopaxi. d) Hillshaded Digital Elevation Model (DEM) of Cotopaxi. The dashed black box shows the location of $\mathbf{b}$ ) and $\mathbf{c})$. 
on 14 August 2015. These explosions were followed by a two week period of near continuous ash and steam venting, before activity declined at the beginning of September 2015, with the eruption ending in November 2015 (Bernard et al., 2016; Gaunt et al., 2016).

\section{Data and methods}

Satellite SAR data involves the transmission of electromagnetic radiation at microwave wavelengths (between $1 \mathrm{~mm}$ and $1 \mathrm{~m}$ ) from the satellite towards the ground surface. On contact with the ground, the radar signal is scattered, with a portion of the signal backscattered toward the satellite, which records a complex number for each pixel imaged. The amplitude of this complex number represents the intensity of the radar signal received and constitutes the proportion of the transmitted energy that was backscattered. The phase of the complex number is equivalent to the fraction of the wavelength (between 0 and $2 \pi$ ) and represents the distance between the satellite and the ground surface, wrapped by modulo $2 \pi$ (e.g. Massonnet and Feigl, 1998).

The phase difference between two radar acquisitions separated in time and/or space is frequently used to provide information about the shape of the land surface or the magnitude and spatial extent of ground deformation associated with volcanic processes (e.g. Pinel et al., 2014). In areas where the land surface changes rapidly, for example due to vegetation growth or emplacement of volcanic deposits, the phase difference between neighbouring pixels observed by Interferometric Synthetic Aperture Radar (InSAR) will appear random (incoherent), and therefore no meaningful information can be retrieved (Fig. 11 c). Phase delays introduced by variation in atmospheric water vapour content can also introduce significant noise that can obscure ground deformation signals (e.g. Parker et al., 2015)(Fig. 11.).

The amplitude component of a SAR image represents the power of the backscattered radar signal observed by the satellite. This amplitude is a function of local slope relative to the SAR incidence angle, the surface roughness on the length scale of the radar wavelength, and the dielectric constant of the surface material, which changes most with the presence or absence of water (Wadge et al., 2011). In addition the SAR amplitude is a function of the relative radar polarization (Zebker et al., 1987; Saepuloh et al., 2012; Solikhin et al., 
2015). However, due to data availability, in this study we only consider single polarization data $(\mathrm{HH})$.

The dielectric constant of a material is a measure of how polarizable that material is, and is defined as an effective complex relative permittivity, $\epsilon=\epsilon^{\prime}-i \epsilon^{\prime \prime}$, where $\epsilon^{\prime}$ is the real and $\epsilon^{\prime \prime}$ is the complex component of relative permittivity (e.g. Adams et al., 1996). For a given material, $\epsilon^{\prime}$ and $\epsilon^{\prime \prime}$ are both dependent on the material density and shape, as well as its temperature and the frequency of incident electromagnetic radiation.

In practice it is not possible to estimate the dielectric constant of the ground surface from the power of radar amplitude in a single image, or predict the radar amplitude if the dielectric constant is known, since the amplitude is dependent on the sum of all scatterers within a ground resolution element (pixel). Variations in the satellite viewing geometry with time mean that for any given pixel the backscattered power will be the sum of a slightly different set of scatterers at each time step, resulting in a pixel-by-pixel speckle pattern. However, by comparing broader scale amplitude variations over multiple neighbouring pixels, changes in observed radar amplitude can still provide useful information about areas that are affected by volcanic eruptions, even when the surface has changed enough to decorrelate SAR phase (Fig. 1).

Lab measurements of $\epsilon^{\prime}$ and $\epsilon^{\prime \prime}$ exist for some materials of interest - for andesitic ash, at X-Band frequency $(9.6 \mathrm{GHz}), \epsilon^{\prime}$ is between 5 and 6 and $\epsilon^{\prime \prime}$ is between 0.1 and 0.2 Adams et al., 1996; Oguchi et al., 2009). For dry snow at X-band frequency $\epsilon^{\prime}$ is $1-2$ and $\epsilon^{\prime \prime}$ is less than $10^{4}$ (Tiuri et al., 1984; Mätzler and Wegmüller, 1987). We would therefore expect a surface covered by andesitic ash to have a higher magnitude radar amplitude return than a surface of identical slope and roughness covered by dry snow.

Snow is a mixture of air, ice and water, and the dielectric constant of snow is highly dependent on the relative proportion of water, which dominates the value of $\epsilon$ (Tiuri et al. 1984). There is sufficient empirical data to derive a parameterisation of $\epsilon^{\prime}$ and $\epsilon^{\prime \prime}$ for wet snow, based on $W_{v}$, the proportion of water in the snow by volume (Tiuri et al., 1984; Kaatze, 1989; Artemov and Volkov, 2014). From this parameterisation, we would expect the snow covered ice-cap of Cotopaxi to have higher $\epsilon^{\prime}$ compared to the snow-free part of 
the andesitic edifice if $W_{v}>0.3$ and a higher $\epsilon^{\prime \prime}$ if $W_{v}>0.03$. The relative permittivity of andesitic ash also increases substantially when covered with thin films of water, however as yet there is no empirical relationship for this behaviour (Oguchi et al., 2009).

We investigated radar amplitude changes at Cotopaxi using data from two satellite SAR missions, TerraSAR-X (TSX) and COSMO-SkyMed (CSK) that were acquired through the Committee on Earth Observation Satellites' Ecuador Volcanoes Supersite. TSX has a repeat observation frequency of 11 days and CSK is a constellation of four satellites, which each have a repeat time of 16 days. Both satellites operate at X-band frequency (wavelength 3.1 $\mathrm{cm}$ ). TSX images were acquired in spotlight viewing mode, which has a $10 \times 10 \mathrm{~km}$ image size and a horizontal pixel spacing of $2 \mathrm{~m}$. CSK images were acquired in stripmap mode, which acquires a swath $40 \mathrm{~km}$ wide at a pixel spacing of $3 \mathrm{~m}$. Both TSX and CSK data were acquired in $\mathrm{HH}$ polarisation.

We processed data from both satellites using the Caltech/JPL InSAR Scientific Computing Environment (ISCE) software (Rosen et al., 2012). TSX data were provided as single-look complex (SLC) images, while CSK data were provided as raw data, which were focused into SLCs with one look in range and azimuth directions to keep full image resolution. We coregistered SLC images using a subpixel amplitude correlation algorithm and resampled the post-eruptive image to the geometry of the pre-eruptive scene (Rosen et al. 2012). We only consider the amplitude component of the SAR images, since at Cotopaxi, the phase component of interferograms decorrelates rapidly on the glaciated ice-cap, and is subject to high atmospheric noise elsewhere (Fig. 1). Sequential images also have large perpendicular baselines, which reduces the phase coherence in interferograms (e.g. Zebker and Villasenor, 1992).

We keep the SAR images in radar viewing geometry due to the lack of a high resolution digital elevation model (DEM) that could be used to geocode the images and to avoid warping of the image that occurs in inaccurately geocoded images at rapidly changing summits of erupting volcanoes (e.g. Wadge et al., 2011; Ebmeier et al., 2013; Arnold et al., 2016). SAR images in radar viewing geometry are subject to geometric distortion compared to orthorectified geocoded images. Slopes that face towards the satellite sensor will appear brighter and 
compressed, while slopes that face away from the radar look direction will appear darker and stretched. Where the angle of the slope is steeper than the satellite incidence angle, slopes facing away from the satellite will cast a radar shadow. The height of the feature casting the shadow is given by

$$
h=w_{\text {range }} \cos \theta
$$

where $h$ is the height of the feature, $w_{\text {range }}$ is the width of the shadow in the range direction in satellite radar geometry, and $\theta$ is the satellite incidence angle. Conversely, for slopes facing the satellite that are steeper than the normal to the incidence angle, returns from multiple backscatterers will overlap to create radar layover. The height of the feature causing layover is given by

$$
h=\frac{w_{\text {range }} \sin \alpha}{\sin (\alpha-\theta)}
$$

where $\alpha$ is the gradient of the feature causing layover.

Changes in surface reflectivity between two radar images are easier to visualise when plotted either as ratio maps (Wadge et al., 2002) or change difference maps (Wadge et al. 2011). A map of the pixel-by-pixel ratio between two images suppresses the influence of the local slope on amplitude in areas that do not change between images, and decreases the effect of speckle (e.g. Wadge et al., 2002; Bovolo and Bruzzone, 2005). To reduce the contrast between high and low intensity pixels, the change in ratio $\mathbf{X}_{\mathbf{R}}$ is given in decibels by taking the base 10 logarithm of the ratios (Rignot and van Zyl, 1993).

$$
\mathbf{X}_{\mathbf{R}}=10 \log _{10}\left(\frac{\mathbf{X}_{\mathbf{2}}}{\mathbf{X}_{\mathbf{1}}}\right)
$$

where $\mathbf{X}_{1}$ is the intensity of the earlier image and $\mathbf{X}_{\mathbf{2}}$ is the intensity of the later image. Pixels in the ratio map with a value greater than $0 \mathrm{~dB}$ represent an increase in amplitude between the two acquisition dates, while pixels less than $0 \mathrm{~dB}$ have a decreased amplitude.

Alternatively, we can display differences in backscatter intensity as a change difference image. Change difference images are easier to interpret than ratio maps, but display reduced changes in areas of high amplitude, such as slopes facing towards the satellite Rignot and van Zyl, 1993; Wadge et al., 2011). To generate a change difference image, we create a 
three-colour component image. Following Wadge et al. (2011); Ebmeier et al. (2014) we assign the earlier image to the red band, the later image to the green band and the scaled difference between the two images to the blue band. Surfaces that have increased reflectivity between the two acquisition dates will appear cyan in a change difference image, surfaces that have decreased reflectivity will appear magenta, and surfaces that have not changed reflectivity will appear yellow.

\section{Results}

We form change difference and ratio maps spanning the initial explosive activity at Cotopaxi on 14 August 2015 (Figs. 2 and 3). Both maps show complex spatial variations in radar amplitude associated with the eruption, on the ice-cap near the crater and on the flanks and plateau surrounding Cotopaxi, below the ice-cap.

\subsection{Crater morphology}

The most significant amplitude changes observed at Cotopaxi were at the summit, within approximately $1 \mathrm{~km}$ of the crater. Both TSX and CSK images observe a large decrease in amplitude inside the crater ( $\mathrm{A}$ in Fig. 2, $\mathrm{B}$ in Fig. (4). The spatial pattern of the amplitude decrease is consistent with an increase in the width of shadow cast by the crater wall closer to the satellite. Using equation 1, we find that the height of the crater wall increased by $58 \pm 4$ $\mathrm{m}$ in the TSX imagery and $51 \pm 5 \mathrm{~m}$ in CSK images. Since the geometry of the crater edge remains effectively unchanged between pre- and post-eruptive images, this height change must be caused by a lowering of the crater floor through removal of material by volcanic explosions (Fig. 4 e and d). Note that for both satellites the height change given is a lower bound, as the shadow cast by the near crater wall is interrupted by layover.

If we make assumptions about the shape of the summit crater, then we can estimate the volume of material that was removed by the explosive activity. The crater rim is approximately circular, with a radius of $90 \pm 5 \mathrm{~m}$ (Fig. 2). If we consider the crater to be conical, from the TSX images, the bulk volume removed between the start of eruption on 14 and 20 August 2015 was $5 \pm 2 \times 10^{5} \mathrm{~m}^{3}$. Alternatively, if we assume the crater has vertical 
sides then the volume removed during this time period was $1.5 \pm 6 \times 10^{6} \mathrm{~m}^{3}$. Realistically the actual volume removed from the crater is likely to be between these end member cases. Bernard et al. (2016) estimated an erupted volume of $1.18 \pm 0.33 \times 10^{5} \mathrm{~m}^{3}$ between 14 and 15 August 2015, with little volume erupted between 15 and 22 August based on isopleth maps of tephra mass. Our volume estimates for this time period are substantially greater than that observed from tephra deposition, so a relatively large proportion of the volume removed from the crater must have been deposited proximally to the crater, possibly as ballistic projectiles, which were observed on the upper slopes of Cotopaxi on 14 August 2015 (Bernard et al., 2016).

\subsection{Proximal ash}

Areas of bare rock within and proximal to the crater show a slight increase in amplitude (B in Fig. 2), while ice and snow covered areas north, east and south of the crater all show decreased amplitude ( $\mathrm{C}$ in Fig. 2 and 4 ). Given the proximity to the eruptive vent and the rapid lateral changes between areas of increased and decreased amplitude on the flanks of Cotopaxi, it is likely that these differences were caused by variation in the pre-eruptive surface (ice or rock), rather than significant differences in the deposition during the eruption (Fig. 4e and f).

We assume that the erupted material in 2015 was similar in composition to previously erupted products at this elevation on the edifice of Cotopaxi, therefore there should not be any significant difference in dielectric constant between old and new deposits. The increased amplitude on bare rock therefore suggests that the proximal post-eruptive surfaces were rougher than the pre-eruptive surface. For X-band $(3.1 \mathrm{~cm}$ wavelength) radar, surfaces appear rough if the small scale height variation is greater than about $4 \mathrm{~mm}$ (Wadge et al. 2011). While most of the erupted material from this time period was fine-grained tephra, proximal deposits contained approximately $2 \%$ lapilli $(2-4 \mathrm{~mm})$ and larger ballistic projectiles were observed on the upper flanks (Bernard et al., 2016; Gaunt et al., 2016). For a given pixel in a SAR image, the backscatter is dominated by the largest objects contained within that pixel (e.g. Ferretti et al., 2000; Hooper et al., 2004), therefore even a small proportion 
of coarse grained lapilli and ballistics could be enough to increase the surface roughness at radar wavelengths.

Ice and snow covered areas within $1 \mathrm{~km}$ of the summit crater show a clear decrease in radar backscatter by over $5 \mathrm{~dB}$ (Fig. $2 \mathrm{~b}$ and $\mathrm{d}$ ). This decrease in reflected power would be expected if the glacier was covered with tephra that had a lower dielectric constant than the glacier. However, aerial photographs acquired on 18 August show little to no tephra on the north, east and south flanks of the glacier. Instead, this change might be due to changes in the ice-cap, such as fresh dry snow covering older wet snow at high altitudes. While the greatest thickness of ash deposits were on the west flank of Cotopaxi, the radar information provide little information about the ice-cap on the west flank, which suffers from layover in ascending TSX images, and is almost entirely in shadow in descending CSK images.

\subsection{Ice-cap and crevasses}

We observed crevasses on the west flank (D in Fig. 2 and 4 ) that provided a reflective surface facing the CSK satellite. The steep sided crevasses appear as patches of layover, which more than halved in width between the pre-eruptive and post-eruptive images. If we assume that the crevasses have vertical sides, then using equation 2 , we estimate that they decreased in height from $15 \pm 2 \mathrm{~m}$ to $6 \pm 2 \mathrm{~m}$. Increased geothermal heating from below combined with conductive heat transfer from tephra deposited on top of the glacier resulted in high rates of glacier melting between August 18 and October 82015 compared to the background rate (Ramón et al., 2016). However, it is highly unlikely that the observed 9 $\mathrm{m}$ decrease in crevasse height was due to melting, since this height decrease across the west flank of the ice-cap would generate a very large volume of meltwater, which wasn't observed at the time (IG-EPN special reports).

The $9 \mathrm{~m}$ decrease in crevasse depth could be due to infill by tephra and lapilli, however the measured tephra mass for this time period was $7600 \mathrm{~g} \mathrm{~m}^{-2}$ at the nearest location to the glacier (Fig. 3g) (Bernard et al., 2016). The measured ash deposit density was $1343 \pm$ $128 \mathrm{~kg} \mathrm{~m}^{-3}$ (Bernard et al., 2016), which gives a deposit thickness of $6 \mathrm{~mm}$ - orders of magnitude less than required to account for the change in crevasse height. However, glacier 


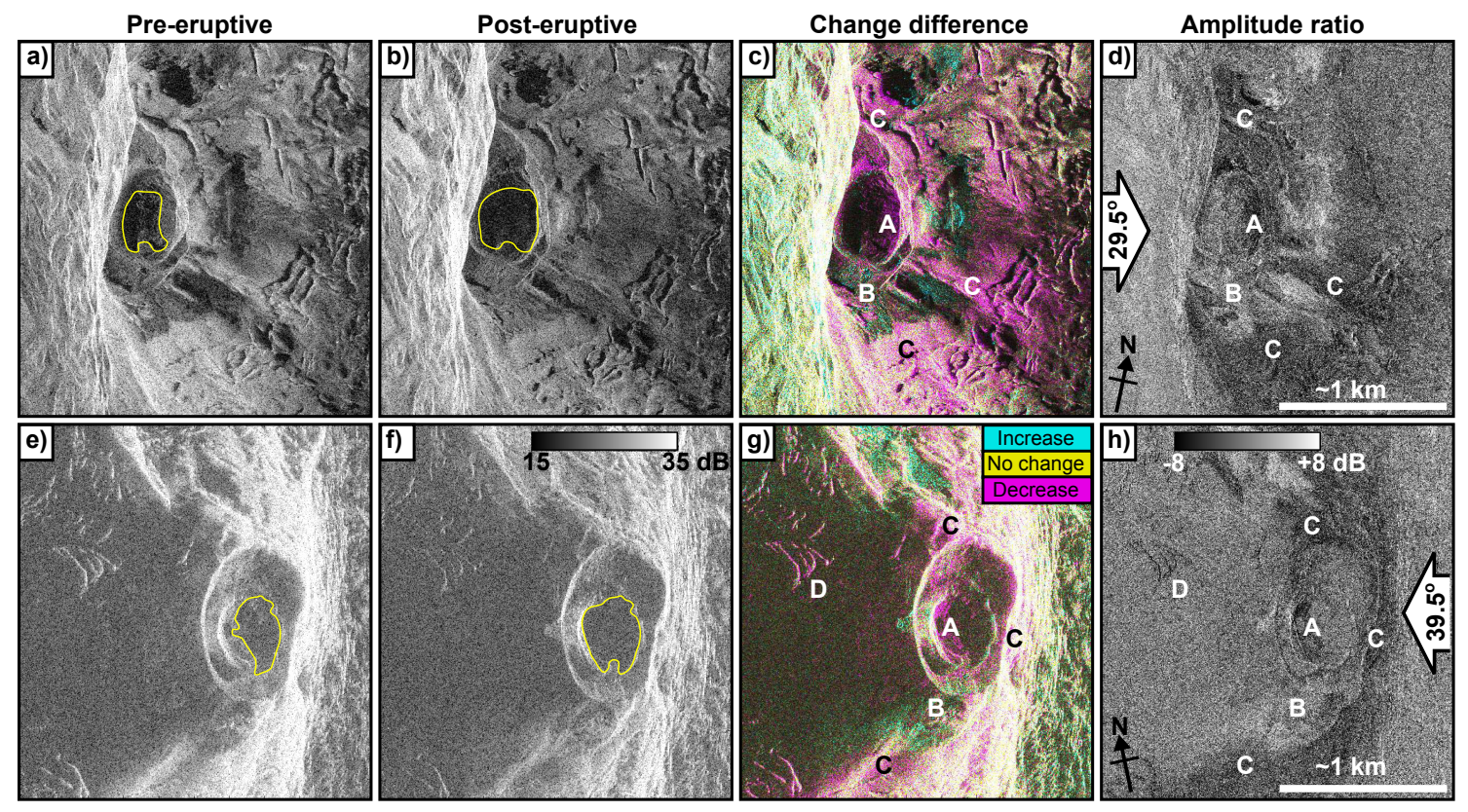

Figure 2: TSX (top) and CSK (bottom) images of the summit of Cotopaxi volcano during the August 2015 eruption. a) and e) pre-eruptive images; b) and $\mathbf{f}$ ) post-eruptive images; c) and $\mathbf{g}$ ) change difference maps; d) and $\mathbf{h}$ ) amplitude ratio maps. TSX images were acquired on ascending passes in spotlight mode on 9 August 2015 (a) and 20 August 2015 (b). CSK images were acquired in stripmap mode on descending passes on 12 August 2015 (e) and 28 August 2015 (f). Images are in radar viewing geometry, with the white arrows showing the satellite look direction and incidence angle. Yellow polygons in a), b), e) and f) indicate the area of radar shadow in the summit crater. The scale bars are approximately accurate in the azimuth direction (perpendicular to the look direction), but are not valid on sloped topography in the range direction (parallel to the look direction). See main text for references to labels A-D. 
meltwater or precipitation could wash tephra deposits into the crevasses, where they would accumulate a much greater thickness than if tephra was just deposited by airfall. Partial collapse of the crevasse sides, potentially induced by partial melting, would also move ice from the top of the crevasse to the base, reducing the height of the crevasse side causing the layover (Fig. $4 \mathrm{~g}$ and $\mathrm{h}$ ).

On the north, east and south side of the glacier is a ring of amplitude increase in both TSX and CSK imagery (C in Fig. 3, A in Fig. 4). These areas were upwind of the summit, and not affected by ashfall (Bernard et al., 2016), however visual observations on 18 and 23 August observed increased moisture and streams of water descending from the basal edge of the glacier (Fig. 4a; Ramón et al., 2016). Increasing the water content of the area around the glacier would increase the permittivity of the reflecting surface, resulting in the increased amplitude observed (Oguchi et al., 2009). The paired inner ring of decreased amplitude observed in Fig. 3b cannot be explained by the same mechanism, but could be due to the presence of dry snow in the pre-eruptive image that had melted by the later image.

\subsection{Distal amplitude changes}

Changes in radar amplitude were observed up to $10 \mathrm{~km}$ away from the summit and below the glacier. The area to the west of the summit, a few kilometres distal from the glacier edge, shows increased amplitude in the CSK image, but is not covered by the smaller footprint of the spotlight TSX image (A in Fig. 3). This area was covered by the greatest thickness of tephra deposits, with over $7000 \mathrm{~g} \mathrm{~m}^{-2}$ of ash deposition between 14 and 28 August 2015 (Bernard et al., 2016), and is immediately downwind of the Cotopaxi summit. Given the fine-grained nature of the tephra fallout (Gaunt et al., 2016), we would expect the surface roughness to decrease when covered by a layer of tephra (e.g. Wadge et al., 2011).

We propose two possible mechanisms to explain the localised amplitude increase that is spatially correlated with the thickest tephra deposits. The first mechanism involves initially lowering the surface roughness through tephra deposition. The tephra deposits are poorly consolidated and therefore more rapidly eroded than older, more consolidated, deposits by post-depositional rainfall, which creates micro-relief that is rougher than the pre eruption 


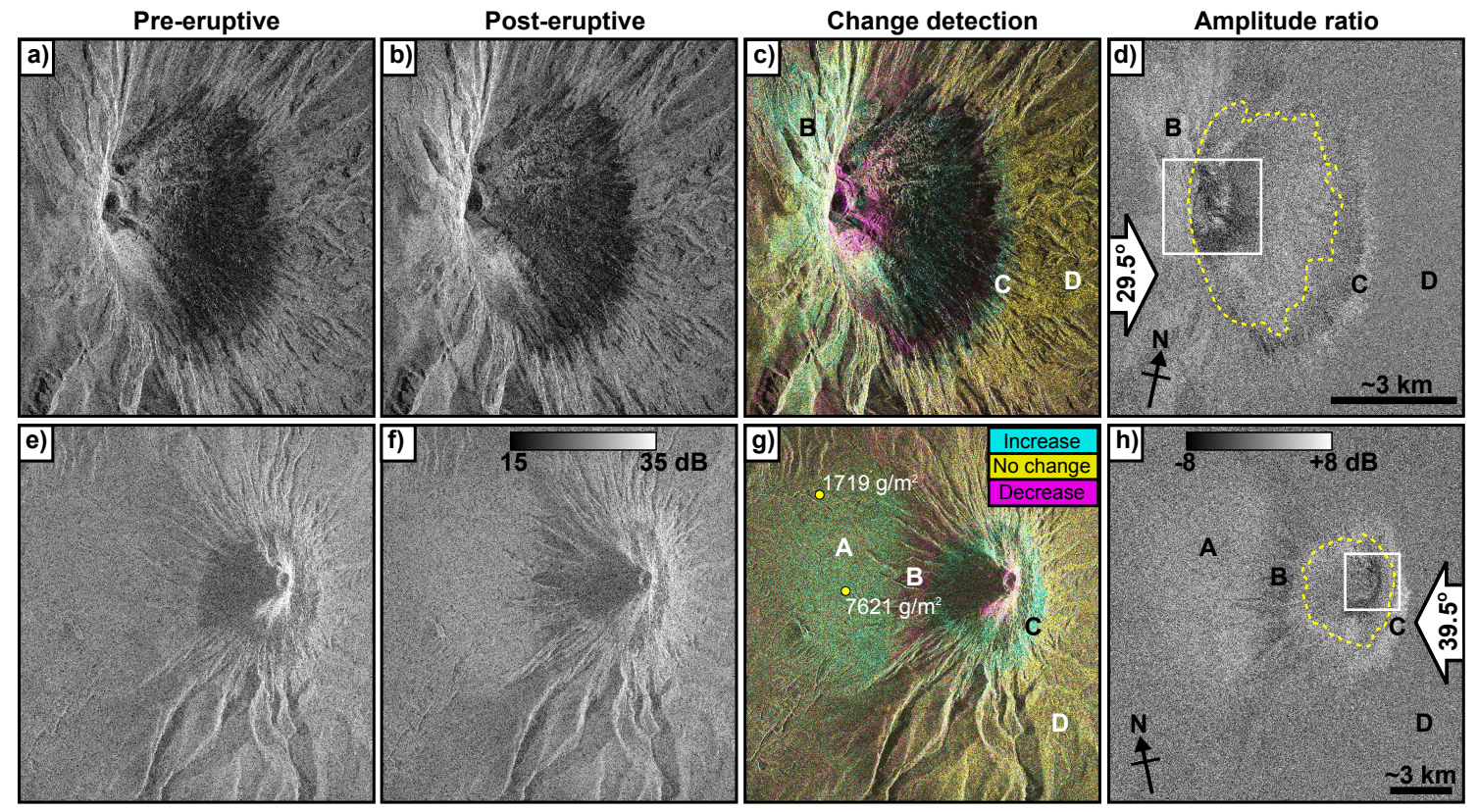

Figure 3: TSX (top) and CSK (bottom) images of the flanks of the August 2015 eruption of Cotopaxi. a) and $\mathbf{e}$ ) pre-eruptive images; $\mathbf{b}$ ) and $\mathbf{f}$ ) post-eruptive images; $\mathbf{c}$ ) and $\mathbf{g}$ ) change difference maps; $\mathbf{d}$ ) and h) amplitude ratio maps. TSX images were acquired on ascending passes in spotlight mode on 9 August 2015 (a) and 20 August 2015 (b). CSK images were acquired in stripmap mode on descending passes on 12 August 2015 (e) and 28 August 2015 (f). Images are in radar viewing geometry, with the white arrows showing the satellite look direction and incidence angle. The scale bars are approximately accurate in the azimuth direction (perpendicular to the look direction), but are not valid on sloped topography in the range direction (parallel to the look direction). Yellow dashed lines in $\mathbf{d}$ ) and $\mathbf{h}$ ) show the edge of the ice-cap, and white boxes show the extent of Fig. 2. See main text for references to labels A-D. 
surface (combining steps b and d from Fig. 1 of Wadge et al. (2011)). While we cannot rule out this mechanism, the nearest weather station (located $30 \mathrm{~km}$ to the southwest at Cotopaxi International Airport in Latacunga) recorded very little precipitation between 14 and $28 \mathrm{Au}-$ gust 2015 (NOAA Global Surface Summary of the Day records, available online at https:// www7.ncdc .noaa.gov/CDO/cdoselect. cmd?datasetabbv=GSOD\&resolution=40). There were also near continuous ash emissions during the last week in August (Bernard et al., 2016, Gaunt et al., 2016), therefore providing constant resurfacing of the surface that would mitigate against this effect.

Alternatively, the effective permittivity of andesitic ash greatly increases when covered by a thin film of water (Oguchi et al., 2009). If the erupted ash was covered by a coat of water, either acquired from meteorological clouds or a hydrothermal or phreatic source, and the deposited tephra had not dried out by the time the second SAR image was acquired, the area covered by ash would have an increase in radar backscatter, even if the surface roughness was decreased. Given the phreatic nature of the initial explosive phase Gaunt et al., 2016), high glacier melt rates (Ramón et al., 2016), and frequent orographically forced cloud around the summit of Cotopaxi (Fig. 4a), we suspect this "wet ash" mechanism is more likely than post-depositional erosion. Wetted ash could also explain the amplitude increase seen near to the crater (B in Fig. 2), even if the proximal ash was fine-grained.

Closer to the summit, west and northwest of the glacier there were amplitude changes in both TSX and CSK imagery, but with differing sign (B in Fig. 3, E in Fig. 4). The TSX pair shows amplitude increase, while the CSK pair shows decreased amplitude in the same area. This area is on the flank of Cotopaxi, which slopes $20-30^{\circ}$ to the west. Covering the slope with ash will decrease the surface roughness, which will change the amount of backscattered energy received by the satellite depending on the incidence angle of the SAR signal. Reducing roughness will cause the surface to act more like a specular reflector, which will reflect more energy back towards the east-looking, ascending pass (TSX) while more energy will be reflected away from the west looking, descending pass (CSK) causing a reduction in SAR amplitude (Fig. 4 and $\mathrm{j}$ ).

To the north, east and south, and at distances greater than $5 \mathrm{~km}$ from the summit of 


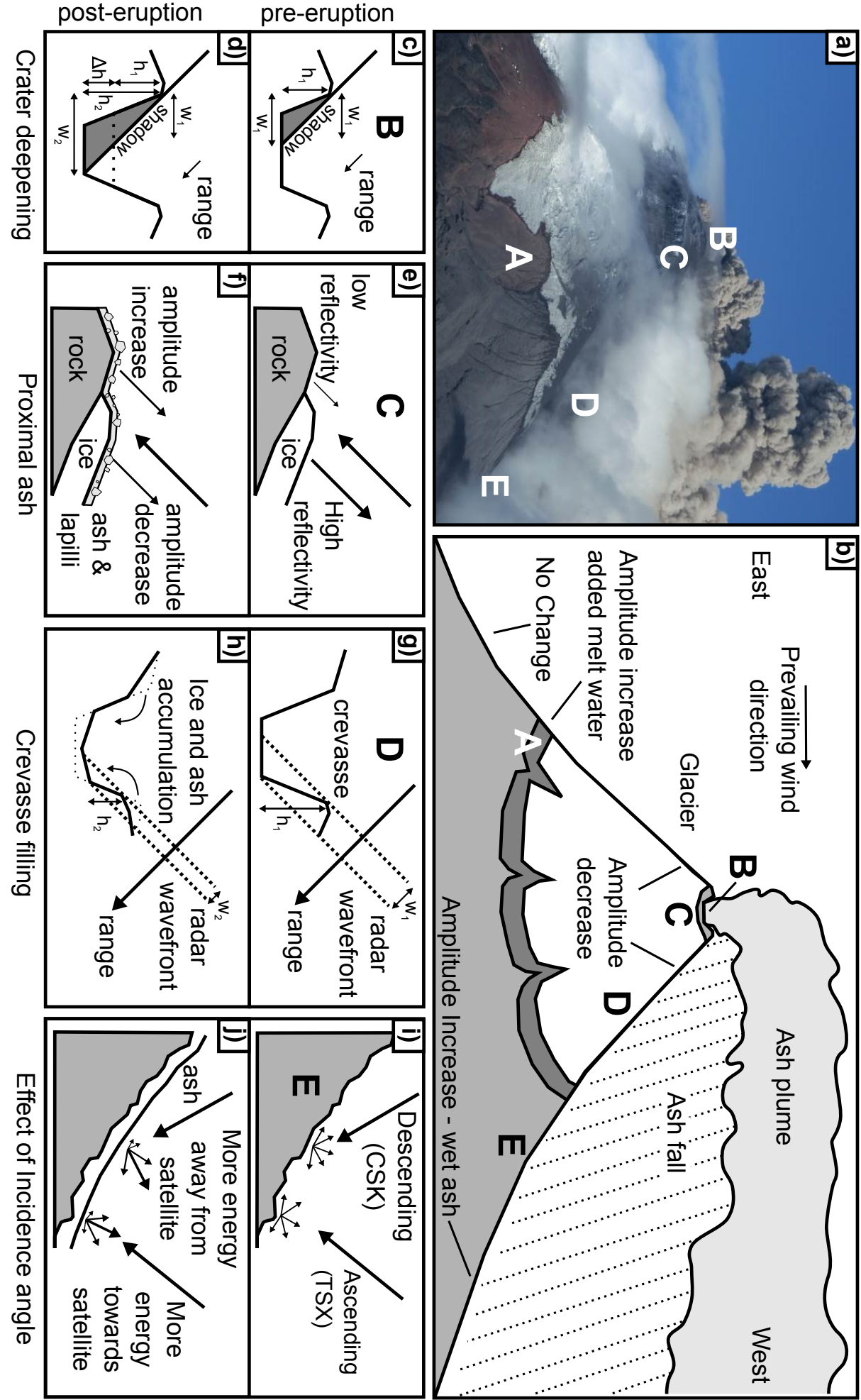


Cotopaxi, there are no significant amplitude changes in either TSX or CSK imagery (D in Fig. 3), showing that these areas were unaffected by the eruption.

\subsection{Baseline measurements of amplitude change}

In addition to volcanic activity, radar amplitude can be affected by changes in precipitation and vegetation cover, and we would therefore expect to observe amplitude variations during inter-eruptive periods (e.g. Wadge et al., 2011; Kubanek et al., 2017). These amplitude changes can vary systematically throughout the year due to seasonal changes in vegetation growth and precipitation (Kubanek et al., 2017) however, we would not expect a strong seasonal signal at a high altitude equatorial volcano such as Cotopaxi.

In order to determine which amplitude changes are due to eruptive activity, we need background measurements during periods of quiescence to establish a baseline of typical amplitude changes. To create this baseline, we use eight TSX scenes to form four image pairs, each with 11 day separation, acquired throughout the year following the eruption (there is not a sufficiently long catalog of pre-eruptive X-band imagery at Cotopaxi to form a pre-eruption baseline). We follow the same data processing scheme detailed in Section 2 to create four additional post-eruptive change difference images (Fig. 5) that we compare with the syn-eruptive images shown in Figs. 2 and 3

In the post-eruptive change difference images, we observe amplitude variations with different spatial patterns to those seen in the syn-eruptive imagery (Fig. 5 a and $\mathrm{f}$ ). Amplitude changes on the glacier appear more spatially homogenous, such as between 7 and 18 April 2016 (Fig. 5e and h) and between 4 and 15 July 2016 (Fig. 5d and i), where there is an amplitude increase across the entire Cotopaxi glacier. Post-eruptive images also show no change in amplitude west of the summit, supporting our interpretation that the syn-eruptive amplitude changes on the western flank were due to ashfall.

Proximal to the Cotopaxi crater, between 22 October and 2 November 2016 (Fig. 5p) we observe amplitude variations that have a similar spatial pattern to the syn-eruptive changes, with decreased amplitude on ice covered ground and decreased amplitude on exposed rock. Since there was no eruptive activity at Cotopaxi in 2016, the pattern in the post-eruptive 


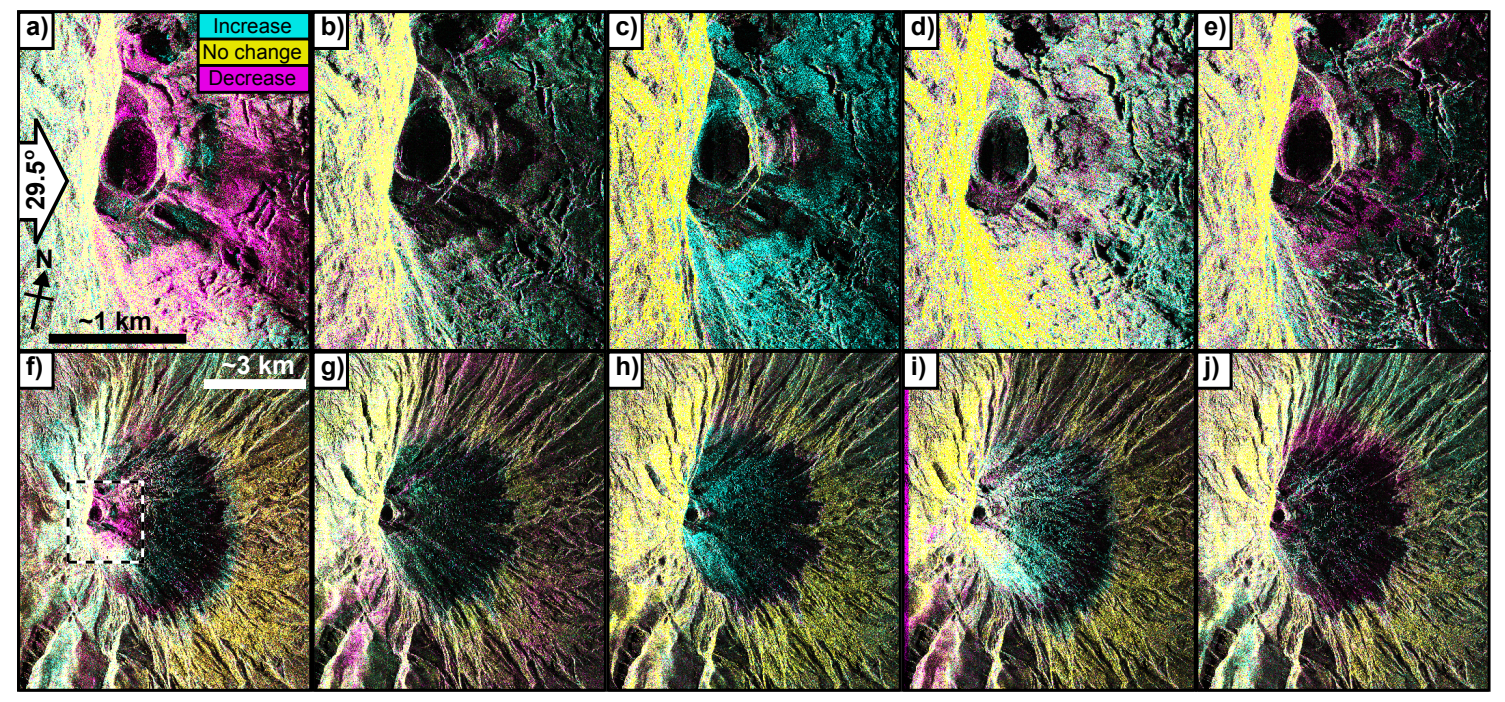

Figure 5: Change difference images of Cotopaxi formed from the 11-day TSX image pairs acquired on ascending passes in spotlight mode. a) and f) are the syn-eruptive images from 12 - 28 August 2015 (Fig. 25 and 35). b)-e) and $\mathbf{g})-\mathbf{j})$ are post-eruptive image pairs collected throughout 2016. b) and g) $10-$ 21 January 2016; c) and h) 7-18 April 2016; d) and i) 4-15 July 2016; e) and j) 22 October - 2 November 2016. The dashed black and white box in $\mathbf{f}$ ) give the location of zoomed images a) $-\mathbf{e})$.

imagery cannot be due to deposition of ash and lapilli (Fig. 4p and f). However, snowfall between the two image acquisition dates could cause a similar pattern, with snow deposited onto rock causing an amplitude increase, while depositing fresh dry snow onto wetter snow would appear as an amplitude decrease. Fig. 5j shows that there are concentric amplitude variations on the cone, which are likely due to altitude and temperature differences in the structure and water content of fresh snowfall between the images (Tiuri et al., 1984; Kaatze, 1989; Artemov and Volkov, 2014).

\section{Discussion}

\subsection{Application of radar amplitude to volcanoes}

Here we have demonstrated the ability of radar amplitude images to record changes in surface character associated with explosive eruptive activity at a glaciated volcano. Radar amplitude was used to retrieve information about changes to the crater and ice-cap of Cotopaxi, even where radar phase was incoherent (Fig. 11.). Only processing the amplitude 
component of SAR images also provides a substantial reduction in processing time, which can be crucial when responding to a rapidly evolving volcanic system. In particular, the computationally expensive steps of topographic flattening, filtering and phase unwrapping can all be skipped when only dealing with amplitude imagery (e.g. Werner et al., 2000, Rosen et al., 2004, 2012).

Previous work has shown the benefit of the amplitude images for tracking lava dome growth (Wadge et al., 2011; Pallister et al., 2013; Wang et al., 2015), lava flow development (Wadge et al., 2012; Goitom et al., 2015, Chapters 3 and 4), rockfalls (Ebmeier et al., 2014), and pyroclastic density current and block-and-ash flow deposition (Wadge et al. 2011). Results presented here represent one of the first cases of using radar amplitude to study explosive volcanism and tephra dispersion, and additionally show changes in glacier morphology associated with volcanic activity.

We also show the benefit of comparing results from different satellite sensors and viewing geometries. Higher resolution spotlight TSX imagery was better at observing small scale, localised changes on the glacier and at the summit crater. However, the larger footprint of the stripmap CSK images enabled us to observe more distal ash depositions that fell outside the TSX footprint.

The interpretation of amplitude images can be greatly aided by validation data, such as field measurements of ashfall thickness (Bernard et al., 2016). For example, the edge of the area that shows significant amplitude variation due to ashfall (A in Fig. 3) approximately intersects with a location where Bernard et al. (2016) measured $1719 \mathrm{~g} \mathrm{~m}^{-2}$ of tephra deposition during the same time period. Using their measured density of $1343 \pm 128 \mathrm{~kg}$ $\mathrm{m}^{-3}$ give a tephra thickness of $1.28 \pm 0.12 \mathrm{~mm}$. Therefore X-band radar amplitude could be used to map tephra deposits of similar composition and with a thickness greater than $\sim 1$ mm. Optical images (e.g. Fig. 4a) of the eruption also aid with the interpretation of changes on and around the glacier, such as increased melt water at the base of the glacier, and confirming that ash deposition was almost entirely concentrated to the west of the summit.

More detail about syn-eruptive changes in volcano morphology could be obtained by adding data from other SAR platforms that operate at different wavelengths. Sentinel-1 
and ALOS-2 both acquire data with a pixel size of 10-20 m, which would be less well suited to tracking small scale, proximal changes. However, the swath width of Sentinel-1 is $250 \mathrm{~km}$ and ALOS-2 is $350 \mathrm{~km}$, therefore both systems could be better suited to tracking distal ashfall. Since the frequency dependence of surface roughness and dielectric constant is known generally in volcanic terrains (e.g. Ford et al., 1998), observations of the same area at X-band $(\lambda=3.1 \mathrm{~cm}$, e.g. CSK, TSX), C-band $(\lambda=5.6 \mathrm{~cm}$, e.g. Sentinel-1) and L-band $(\lambda=23.6 \mathrm{~cm}$, e.g. ALOS-2) should make it possible to better attribute changes in radar amplitude to either changes in surface roughness or dielectric constant. However, quantitative interpretation of amplitude changes requires more laboratory measurements of how the dielectric constants of surfaces change when covered by volcanic products of different types (e.g. Ulaby and Long., 2014).

\subsection{Volcanic hazard}

Radar amplitude imaging can be a valuable tool for volcano monitoring, and can either supplement other observation techniques, or provide critical information about volcanic hazard when visual observations are not possible (e.g. Wadge et al., 2011; Pallister et al., 2013). As demonstrated here, radar amplitude can be particularly useful for assessing changes at ice-capped volcanoes, where radar phase rapidly decorrelates. Given that both the deadliest (Nevado del Ruiz, 1985: 23000 fatalities, e.g. Pierson et al., 1990) and the most costly (Eyjafjallajökull, 2010: \$5 billion, e.g. International Air Transport Association, 2011) eruptions of recent decades have both involved volcano-ice interactions, ice-capped volcanoes, such as Cotopaxi, pose a much greater potential hazard through primary lahar generation than similar volcanoes that do not have an ice-cap, and generally generate smaller secondary lahars (e.g. Tungurahua: Loughlin et al., 2015; Mothes and Vallance, 2015).

The amplitude images presented here can readily be processed within hours of receiving the satellite data, and incorporated into real-time volcano monitoring. Due to a five day latency period between satellite acquisition and image delivery by DLR, IG-EPN were unable to incorporate TSX images into their real-time monitoring procedures, however later radar amplitude images confirmed aerial and ground-based observations that had been made im- 
mediately after the 14 August 2015 eruption. Image delivery times are more rapid for other SAR platforms - CSK interferograms were successfully incorporated into IG-EPN daily briefings during a period of unrest at Volcan Chiles-Cerro Negro in October 2014 (Ebmeier et al. 2016, Pritchard et al., in prep.), and Sentinel-1 interferograms have been included in IG-EPN special reports on unrest at Cerro Azul in March 2017 (IG-EPN, 2017).

When interpreting amplitude changes, frequent image acquisitions can aide interpretation (e.g. Wadge et al., 2011). Any amplitude changes observed are the cumulative sum of all changes that occurred between the first and second date, therefore attributing amplitude changes to a specific event or time period can be more difficult for change difference maps spanning a longer time interval. Having access to local meteorological records could prove very useful in this regard. However, amplitude changes can be measured even when there are large temporal or perpendicular baselines between images. So, unlike differential InSAR, ratio maps can be generated even if the previous image was acquired months or years previously, which can be a serious limitation for differential InSAR (e.g. Ebmeier et al., 2013).

\section{Conclusion}

We use radar amplitude images from the high resolution TerraSAR-X and COSMO SkyMed satellites to track changes associated with mild explosive volcanism at Cotopaxi, Ecuador in August 2015. We observe spatially complex variations in radar backscatter with adjacent areas showing simultaneous increases and decreases in radar amplitude. We also show that some amplitude changes, due to smoothing of surfaces on sloped topography, are dependent on the radar incidence angle. These surfaces show increased amplitude for satellites facing orthogonal to the slope and decreased amplitude for satellites looking obliquely at the slope. We attribute changes in radar amplitude to a variety of processes, including changes in summit crater morphology and deepening of the crater floor, deposition of ash and lapilli on the summit ice-cap, accumulation of ice and volcaniclastic material at the base of crevasses, increased melt water at the base of the glacier and downwind deposition of wet ash. Radar amplitude images presented here can provide critical information about changes 
to volcanic systems, even when radar phase provides no useful information, and could be used to supplement volcano monitoring observations at other eruptions across the range of terrestrial volcanic settings and eruption styles.

\section{Acknowledgements}

We thank K. Cashman and T. Walter for useful feedback and discussion. Comments from E. Kasischke and one anonymous reviewer greatly improved the manscript. DA is supported by NERC studentship Ne/L501554/1. JB and GW are supported by NERC COMET and JB is supported by STREVA. COSMO-SkyMed data were provided by the Italian Space Agency (ASI) and TerraSAR-X images were provided by Deutsches Zentrum für Luft- und Raumfahrt e. V. (DLR; German Space Agency). Satellite data were made available through the Group on Earth Observation's Ecuador Volcanoes Geohazard Supersite. This work forms part of the Committee on Earth Observation Satellites (CEOS) Volcano Pilot for Disaster Risk Management.

\section{References}

Adams, R.J., Perger, W.F., Rose, W.I., Kostinski, A., 1996. Measurements of the complex dielectric constant of volcanic ash from 4 to 19 GHz. J. Geophys. Res. 101, 8175. URL: http://www.geo.mtu.edu/\{ \}raman/ papers/AdamsJGR.pdf, doi $10.1029 / 96$ JB00193

Arnold, D.W.D., Biggs, J., Wadge, G., Ebmeier, S.K., Odbert, H.M., Poland, M.P., 2016. Dome growth, collapse, and valley fill at Soufrière Hills Volcano, Montserrat, from 1995 to 2013: Contributions from satellite radar measurements of topographic change. Geosphere 12, 1300-1315. URL: http://geosphere . gsapubs.org/lookup/doi/10.1130/GES01291.1, doi:10.1130/GES01291.1.

Artemov, V.G., Volkov, A.A., 2014. Water and Ice Dielectric Spectra Scaling at 0C. Ferroelectrics 466,

a 158-165. URL: http://arxiv.org/abs/1308.1229http://www.tandfonline.com/doi/abs/10.1080/ 00150193.2014.895216, doi:10.1080/00150193.2014.895216, arXiv:1308.1229

Bernard, B., Battaglia, J., Proaño, A., Hidalgo, S., Vásconez, F., Hernandez, S., Ruiz, M., 2016. Relationship between volcanic ash fallouts and seismic tremor: quantitative assessment of the 2015 eruptive period at Cotopaxi volcano, Ecuador. Bull. Volcanol. 78, 80. URL: http://link.springer.com/10.1007/ s00445-016-1077-5, doi:10.1007/s00445-016-1077-5

Biggs, J., Pritchard, M.E., 2017. Global Volcano Monitoring: What Does It Mean When Volcanoes Deform? 
Elements 13, 17-22. URL: http://elements.geoscienceworld.org/content/13/1/17, doi 10.2113/ gselements.13.1.17

Bovolo, F., Bruzzone, L., 2005. A detail-preserving scale-driven approach to change detection in multitemporal SAR images. IEEE Trans. Geosci. Remote Sens. 43, 2963-2972. URL: http://ieeexplore.ieee. org/document/1542367/, doi:10.1109/TGRS.2005.857987.

Ebmeier, S.K., Biggs, J., Mather, T.A., Amelung, F., 2013. Applicability of InSAR to tropical volcanoes: insights from Central America. Geol. Soc. London, Spec. Publ. 380, 15-37. URL: http: //sp.lyellcollection.org/content/380/1/15.short, doi:10.1144/SP380.2.

Ebmeier, S.K., Biggs, J., Muller, C., Avard, G., 2014. Thin-skinned mass-wasting responsible for widespread deformation at Arenal volcano. Front. Earth Sci. 2, 1-10. URL: http://journal.frontiersin.org/ article/10.3389/feart.2014.00035/abstract, doi:10.3389/feart.2014.00035

Ebmeier, S.K., Elliott, J.R., Nocquet, J.M., Biggs, J., Mothes, P., Jarrín, P., Yépez, M., Aguaiza, S., Lundgren, P., Samsonov, S.V., 2016. Shallow earthquake inhibits unrest near Chiles-Cerro Negro volcanoes, Ecuador-Colombian border. Earth Planet. Sci. Lett. 450, 283-291. URL: http://www. sciencedirect. com/science/article/pii/S0012821X16303338, doi:10.1016/j.epsl.2016.06.046.

Elliott, J., Walters, R., Wright, T., 2016. The role of space-based observation in understanding and responding to active tectonics and earthquakes. Nat. Commun. 7, 13844. URL: http://www.ncbi.nlm. nih.gov/pubmed/28004655, doi $10.1038 /$ ncomms13844.

Ferretti, A., Prati, C., Rocca, F., 2000. Nonlinear subsidence rate estimation using permanent scatterers in differential SAR interferometry. IEEE Trans. Geosci. Remote Sens. 38, 2202-2212. URL: http: //ieeexplore.ieee.org/document/868878/, doi 10.1109/36.868878

Ford, J., Blom, R., Jr, J.C., Farr, T., Plaut, J., 1998. Radar geology, in: Henderson, F., Lewis, A. (Eds.), Princ. Appl. imaging radar. Man. Remote sensing, Vol. 2. John Wiley and Sons, Inc., Somerset, NJ (United States), pp. 511-560. URL: https://scholar.google.co.uk/scholar?q=Ford\{\%\}2C+J.P. $+\{\%\} 281998\{\%\} 29+$ Radar+geology $\cdot\{\&\}$ btnG $=\{\&\}$ hl $=$ en $\{\&\}$ as $\left\{\_\right\}$sdt $=0\{\%\} 2 C 5$.

Gaunt, H.E., Bernard, B., Hidalgo, S., Proaño, A., Wright, H., Mothes, P., Criollo, E., Kueppers, U., 2016. Juvenile magma recognition and eruptive dynamics inferred from the analysis of ash time series: The 2015 reawakening of Cotopaxi volcano. J. Volcanol. Geotherm. Res. 328, 134-146. URL: http://www.sciencedirect.com/science/article/pii/S0377027316301858?np= $\mathrm{y}\{\&\} n$ RKey=93070ef3896dbf4803f0c5b235a6a2d7154de09fd4443ce6de78255becdbd0f2, doi 10.1016/ j.jvolgeores.2016.10.013

Goitom, B., Oppenheimer, C., Hammond, J.O.S., Grandin, R., Barnie, T., Donovan, A., Ogubazghi, G., Yohannes, E., Kibrom, G., Kendall, J.M., Carn, S.A., Fee, D., Sealing, C., Keir, D., Ayele, A., Blundy, J., Hamlyn, J., Wright, T., Berhe, S., 2015. First recorded eruption of Nabro volcano, Eritrea, 2011. 
Bull. Volcanol. 77, 85. URL: http://link.springer.com/10.1007/s00445-015-0966-3, doi 10.1007/ s00445-015-0966-3.

Hooper, A., Zebker, H., Segall, P., Kampes, B., 2004. A new method for measuring deformation on volcanoes and other natural terrains using InSAR persistent scatterers. Geophys. Res. Lett. 31, 1-5. URL: http: //doi.wiley.com/10.1029/2004GL021737, doi:10.1029/2004GL021737.

IG-EPN, 2017. Informe Especial Cerro Azul No. 2 - 2017 - Instituto Geofísico - EPN. URL: http://www. igepn.edu.ec/servicios/noticias/1473-informe-especial-cerro-azul-no-2-2017

International Air Transport Association, 2011. Volcanic Ash. Ashes to AshesWhat has been learned from recent volcanic eruptions and where does the industry go from here? URL: http://airlines.iata. org/analysis/volcanic-ash

Kaatze, U., 1989. Complex permittivity of water as a function of frequency and temperature. J. Chem. Eng. Data 34, 371-374. URL: http://pubs.acs.org/doi/pdf/10.1021/je00058a001http: //pubs.acs.org/doi/abs/10.1021/je00058a001, doi:10.1021/je00058a001.

Kubanek, J., Westerhaus, M., Heck, B., 2017. TanDEM-X Time Series Analysis Reveals Lava Flow Volume and Effusion Rates of the 20122013 Tolbachik, Kamchatka Fissure Eruption. J. Geophys. Res. Solid Earth 122, 7754-7774. URL: http://doi.wiley.com/10.1002/2017JB014309, doi:10.1002/2017JB014309.

LaHusen, R.G., Swinford, K.J., Logan, M., Lisowski, M., 2008. Instrumentation in Remote and Dangerous Settings; Examples Using Data from GPS Spider Deployments During the 20042005 Eruption of Mount St. Helens, Washington. A volcano rekindled renewed Erupt. Mt. St. Helens, 2004-2006 , 335-345URL: https://pubs.usgs.gov/pp/1750/chapters/pp2008-1750\{_\}chapter16.pdf.

Loughlin, S.C., Vye-Brown, C., Sparks, R., Brown, S.K., Barclay, J., Calder, E., Cottrell, E., Jolly, G., Komorowski, J.C., Mandeville, C., Newhall, C., Palma, J., Potter, S., Valentine, G., 2015. An introduction to global volcanic hazard and risk, in: Loughlin, S.C., Sparks, S., Brown, S.K., Jenkins, S.F., Vye-Brown, C. (Eds.), Glob. Volcan. Hazards Risk. Cambridge University Press, Cambridge, pp. 1-80. URL: http: //ebooks . cambridge.org/ref/id/CB09781316276273A013, doi:10.1017/CB09781316276273.003

Massonnet, D., Feigl, K.L., 1998. Radar interferometry and its application to changes in the Earth's surface. Rev. Geophys. 36, 441. URL: http://doi.wiley.com/10.1029/97RG03139, doi:10.1029/97RG03139

Mätzler, C., Wegmüller, U., 1987. Dielectric properties of fresh-water ice at microwave frequencies. J. Phys. D. Appl. Phys. 20, 1623-1630. URL: http://stacks.iop.org/0022-3727/20/i=12/a=013?key= crossref.08de7f831b696e8f0116e5958739ce37, doi:10.1088/0022-3727/21/11/522

Morales Rivera, A.M., Amelung, F., Mothes, P., Hong, S.H., Nocquet, J.M., Jarrin, P., 2017. Ground deformation before the 2015 eruptions of Cotopaxi volcano detected by InSAR. Geophys. Res. Lett. URL: http://doi.wiley.com/10.1002/2017GL073720, doi:10.1002/2017GL073720,

Mothes, P.A., Vallance, J.W., 2015. Lahars at Cotopaxi and Tungurahua Volcanoes, Ecuador: High- 
lights from Stratigraphy and Observational Records and Related Downstream Hazards, in: Volcan. Hazards, Risks, Disasters. Elsevier, pp. 141-168. URL: http://linkinghub.elsevier.com/retrieve/pii/ B978012396453300006X, doi:10.1016/B978-0-12-396453-3.00006-X.

National Academies of Sciences Engineering and Medicine, 2017. Volcanic Eruptions and Their Repose, Unrest, Precursors, and Timing. National Academies Press, Washington, D.C. URL: https://www.nap. edu/catalog/24650, doi $10.17226 / 24650$

Oguchi, T., Udagawa, M., Nanba, N., Maki, M., Ishimine, Y., 2009. Measurements of dielectric constant of volcanic ash erupted from five volcanoes in Japan. IEEE Trans. Geosci. Remote Sens. 47, 1089-1096. URL: http://ieeexplore.ieee.org/document/4798218/, doi:10.1109/TGRS.2008.2008023.

Pallister, J.S., Schneider, D.J., Griswold, J.P., Keeler, R.H., Burton, W.C., Noyles, C., Newhall, C.G., Ratdomopurbo, A., 2013. Merapi 2010 eruption-Chronology and extrusion rates monitored with satellite radar and used in eruption forecasting. J. Volcanol. Geotherm. Res. 261, 144-152. doi:10.1016/j. jvolgeores.2012.07.012.

Parker, A.L., Biggs, J., Walters, R.J., Ebmeier, S.K., Wright, T.J., Teanby, N.A., Lu, Z., 2015. Systematic assessment of atmospheric uncertainties for InSAR data at volcanic arcs using large-scale atmospheric models: Application to the Cascade volcanoes, United States. Remote Sens. Environ. 170, 102-114. URL: http://www.sciencedirect.com/science/article/pii/S0034425715301267, doi $10.1016 /$ j.rse.2015.09.003

Pierson, T.C., Janda, R.J., Thouret, J.C., Borrero, C.A., 1990. Perturbation and melting of snow and ice by the 13 November 1985 eruption of Nevado del Ruiz, Colombia, and consequent mobilization, flow and deposition of lahars. J. Volcanol. Geotherm. Res. 41, 17-66. URL: http://linkinghub.elsevier.com/ retrieve/pii/037702739090082Q, doi:10.1016/0377-0273(90)90082-Q.

Pinel, V., Poland, M., Hooper, A., 2014. Volcanology: Lessons learned from Synthetic Aperture Radar imagery. J. Volcanol. Geotherm. Res. 289, 81-113. URL: http://www.sciencedirect.com/science/ article/pii/S0377027314003084, doi 10.1016/j.jvolgeores.2014.10.010

Pistolesi, M., Rosi, M., Cion, R., Cashman, K.V., Rossotti, A., Aguilera, E., 2011. Physical volcanology of the post-twelfth-century activity at Cotopaxi volcano, Ecuador: Behavior of an andesitic central volcano. Bull. Geol. Soc. Am. 123, 1193-1215. URL: http://gsabulletin.gsapubs.org/cgi/doi/10.1130/B30301.1, doi $10.1130 /$ B30301.1

Pyle, D.M., Mather, T.A., Biggs, J., 2013. Remote sensing of volcanoes and volcanic processes: integrating observation and modelling - introduction. Geol. Soc. London, Spec. Publ. 380, 1-13. URL: http: //sp.lyellcollection.org/content/380/1/1.full, doi:10.1144/SP380.14

Ramón, P., Vallejo, S., Almeida, M., Gomez, J.P., Caceres, B., 2016. Increased Melting of Glaciers during Cotopaxi volcano awakening in 2015, in: EGU Gen. Assem. 2016, held 17-22 April. 2016 Vienna Austria, 
p.10769, p. 10769. URL: http://adsabs .harvard.edu/abs/2016EGUGA..1810769R.

Rignot, E.J.M., van Zyl, J.J., 1993. Change Detection Techniques for ERS-1 SAR Data. IEEE Trans. Geosci. Remote Sens. 31, 896-906. URL: http://ieeexplore.ieee.org/document/239913/, doi:10.1109/36. 239913.

Rosen, P.A., Gurrola, E., Sacco, G.F., Zebker, H.A., 2012. The InSAR scientific computing environment, in: Synth. Aperture Radar, 2012. EUSAR. 9th Eur. Conf., [IEEE], Nuremberg, Germany. pp. 294-297. URL: http://ieeexplore.ieee.org/abstract/document/6217174/

Rosen, P.A., Hensley, S., Peltzer, G., Simons, M., 2004. Updated repeat orbit interferometry package released. Eos, Trans. Am. Geophys. Union 85, 47-47. URL: http://doi.wiley.com/10.1029/ 2004E0050004, doi $10.1029 / 2004 E 0050004$.

Saepuloh, A., Koike, K., Omura, M., 2012. Applying bayesian decision classification to Pi-SAR polarimetric data for detailed extraction of the geomorphologic and structural features of an active volcano. IEEE Geosci. Remote Sens. Lett. 9, 554-558. URL: http://ieeexplore.ieee.org/document/6129474/, doi $10.1109 /$ LGRS.2011.2174611

Scarpa, R., Tilling, R.I., 1996. Monitoring and Mitigation of Volcano Hazards. Springer, Berlin, Heidelberg. URL: http://link.springer .com/10.1007/978-3-642-80087-0, doi 10.1007/978-3-642-80087-0.

Solikhin, A., Pinel, V., Vandemeulebrouck, J., Thouret, J.C., Hendrasto, M., 2015. Mapping the 2010 Merapi pyroclastic deposits using dual-polarization Synthetic Aperture Radar (SAR) data. Remote Sens. Environ. 158, 180-192. URL: http://www.sciencedirect.com/science/article/pii/S0034425714004386, doi $10.1016 /$ j.rse.2014.11.002

Sparks, R.S.J., 2003. Forecasting volcanic eruptions. Earth Planet. Sci. Lett. 210, 115. URL: http://www.sciencedirect.com/science/article/pii/S0012821X03001249, doi 10.1016/ S0012-821X(03) 00124-9.

Sparks, R.S.J., Biggs, J., Neuberg, J.W., 2012. Monitoring Volcanoes. Science (80-. ). 335, 1310-1311. URL: http://science.sciencemag.org/content/335/6074/1310, doi:10.1126/science.1219485

Tilling, R.I., 1989. Volcanic hazards and their mitigation: Progress and problems. URL: http://doi. wiley.com/10.1029/RG027i002p00237, doi:10.1029/RG027i002p00237.

Tilling, R.I., 2008. The critical role of volcano monitoring in risk reduction. Adv. Geosci. 14, 3-11. URL: https://hal.archives-ouvertes.fr/hal-00297038/, doi 10.5194/adgeo-14-3-2008.

Tiuri, M., Sihvola, A., Nyfors, E., Hallikaiken, M., 1984. The complex dielectric constant of snow at microwave frequencies. IEEE J. Ocean. Eng. 9, 377-382. URL: http://ieeexplore.ieee.org/document/ 1145645/, doi:10.1109/JOE.1984.1145645,

Ulaby, F.T., Long., D.G., 2014. Microwave Radar and Radiometric Remote Sensing. Artech House. URL: http://titlealert.alkemlibrary.com/attachments/546/ArtechHouseABI-Mar15-Ulaby.pdf. 
Voight, B., Hoblitt, R.P., Clarke, A.B., Lockhart, A.B., Miller, A.D., Lynch, L., McMahon, J., 1998. Remarkable cyclic ground deformation monitored in real-time on Montserrat, and its use in eruption forecasting. Geophys. Res. Lett. 25, 3405-3408. URL: http://doi.wiley.com/10.1029/98GL01160, doi $10.1029 / 98 \mathrm{GL} 01160$

Wadge, G., Cole, P., Stinton, A., Komorowski, J.C., Stewart, R., Toombs, A., Legendre, Y., 2011. Rapid topographic change measured by high-resolution satellite radar at Soufriere Hills Volcano, Montserrat, 20082010. J. Volcanol. Geotherm. Res. 199, 142-152. URL: http://www.sciencedirect.com/science/ article/pii/S0377027310003434, doi:10.1016/j.jvolgeores.2010.10.011.

Wadge, G., Macfarlane, D., Robertson, D., Hale, A., Pinkerton, H., Burrell, R., Norton, G., James, M., 2005. AVTIS: A novel millimetre-wave ground based instrument for volcano remote sensing. J. Volcanol. Geotherm. Res. 146, 307-318. URL: http://www.sciencedirect.com/science/article/pii/ S0377027305000739, doi $10.1016 / j \cdot j$ jolgeores.2005.03.003

Wadge, G., Saunders, S., Itikarai, I., 2012. Pulsatory andesite lava flow at Bagana Volcano. Geochemistry, Geophys. Geosystems 13, n/a-n/a. URL: http://doi.wiley.com/10.1029/2012GC004336, doi $10.1029 / 2012 \mathrm{GC} 004336$.

Wadge, G., Scheuchl, B., Stevens, N.F., 2002. Spaceborne radar measurements of the eruption of Soufriere Hills Volcano, Montserrat. Geol. Soc. London, Mem. 21, 583-594. URL: http://mem.lyellcollection. org/content/21/1/583.short, doi:10.1144/GSL.MEM.2002.021.01.27.

Wang, T., Poland, M.P., Lu, Z., 2015. Dome growth at Mount Cleveland, Aleutian Arc, quantified by time series TerraSAR-X imagery. Geophys. Res. Lett. 42, 10614-10621. URL: http://doi.wiley.com/10. 1002/2015GL066784, doi 10.1002/2015GL066784.

Watts, R.B., Herd, R.A., Sparks, R.S.J., Young, S.R., 2002. Growth patterns and emplacement of the andesitic lava dome at Soufriere Hills Volcano, Montserrat. Geol. Soc. London, Mem. 21, 115-152. URL: http://mem.lyellcollection.org/content/21/1/115. short, doi:10.1144/GSL. MEM. 2002.021 .01 .06

Werner, C., Wegmüller, U., Strozzi, T., Wiesmann, A., 2000. Gamma SAR and interferometric processing software. Proc. ERS-Envisat Symp URL: http://citeseerx.ist.psu.edu/viewdoc/download?doi= $10.1 .1 .20 .6363\{\&\} r e p=r e p 1\{\&\}$ type $=p d f$.

Werner-Allen, G., Lorincz, K., Welsh, M., Marcillo, O., Johnson, J., Ruiz, M., Lees, J., 2006. Deploying n a wireless sensor network on an active volcano. IEEE Internet Comput. 10, 18-25. URL: http:// ieeexplore.ieee.org/document/1607983/, doi 10.1109/MIC.2006.26.

Zebker, H.A., Villasenor, J., 1992. Decorrelation in interferometric radar echoes. IEEE Trans. Geosci. Remote Sens. 30, 950-959. URL: http://ieeexplore.ieee.org/document/175330/, doi:10.1109/36. 175330 . 
Zebker, H.A., van Zyl, J.J., Held, D.N., 1987. Imagin Radar Polarimetry From Wave Synthesis. J. 645 Geophys. Res. 92, 683-701. URL: http://doi.wiley.com/10.1029/JB092iB01p00683, doi 10.1029/ $646 \quad$ JB092iB01p00683. 